\title{
WALKING THE TIGHTROPE: ONLINE STUDENT ENGAGEMENT EXPERIENCES
}

DO NOT COMPLETE FOR REVIEW SUBMISSION Institution 1, comma, comma, Institution 2 (without titles and addresses), comma, Country - Ariel Narrow, Italic 10 pts, centred, single spacing, after 11, border bottom: single solid line 0.5 pts, 11 pts from text

\begin{abstract}
Studying online is like walking a tightrope for many online students as they try to balance work and caring responsibilities with their learning. This paper reports on a qualitative case study which explored the balancing act of online student engagement experiences. The study followed twenty-four DCU Connected online students over one academic year. The research question for the study was: What themes are central to online student engagement experiences? Data was collected via participant eportfolio entries and through semi-structured interviews and was then analysed thematically. Four key themes were constructed via the analytic process, which included: the importance of community, support networks, balancing study with life, and approaches to learning. The findings indicate that successful online student engagement was influenced by a number of psychosocial factors such as peer community, an engaging online teacher, and confidence and by structural factors such as lifeload and course design.
\end{abstract}

\section{Keywords:}

Online learning, student engagement, student voice

\section{Introduction}

Studying online is like walking a tightrope for many online students as they try to balance work and caring responsibilities with their learning. This case study aimed to explore this balancing act for online students and broader themes relating to their experiences of engagement. The setting for the study was the undergraduate online Humanities degree at DCU Connected. There is a dearth of research about the experiences of online students in the Irish higher education (HE) context, with the majority of the relevant literature based in Australia, "the experiences of online students has been somewhat ignored in the literature" (O' Shea et al., 2015, p. 57). This study aims to address this gap in the literature by increasing our understanding of online student engagement, in the lrish context.

\section{Online Student Engagement}

Student engagement can be defined as "a student's emotional, behavioural and cognitive connection to their study" which has a direct impact on student success and achievement (Kahu, Stephens, Zepke, \& Leach, 2014, p. 523). This section presents contexts from the literature about online student success, learning approaches and engagement through the lens Kahu's (2013) holistic conceptual framework of student engagement which considers the socio-cultural, structural and psychosocial factors aspect, see figure 1 below. 


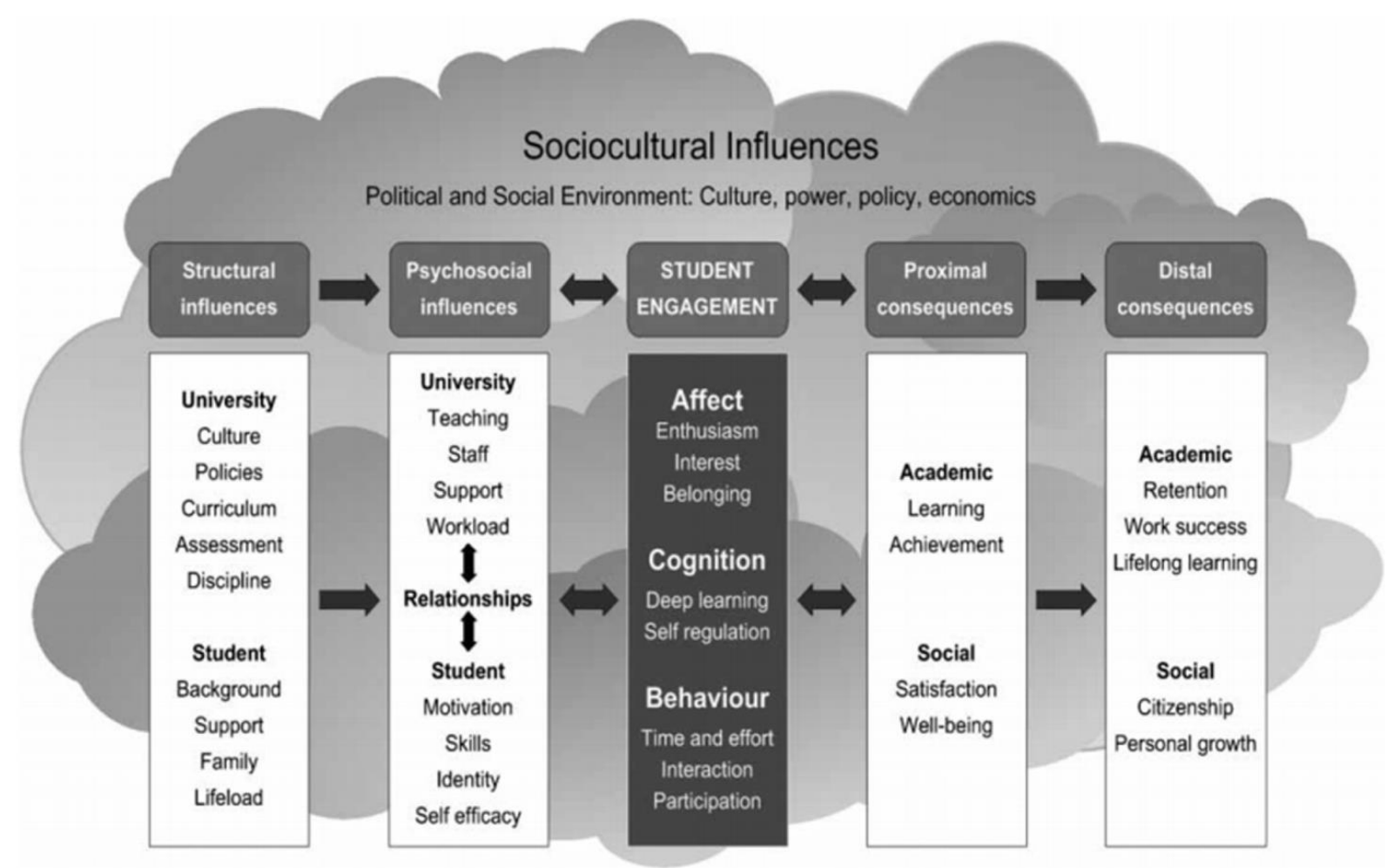

Figure 1. Conceptual framework of engagement, antecedents and consequences (Kahu, 2013, p. 766).

\section{Structural}

There are three key structural influence which impact on online student engagement: course design, institutional supports and lifeload. A well designed online course which encourages interaction, community, clear learning path and real world experiences can support online student engagement (Buck, 2016; Frey, 2015). The campus focused structure of support services such as library, careers, counselling and administration can reduce access to vital university supports for online students (Delaney \& Farren, 2016). This can lead to online students feeling less integrated and having a reduced sense of belonging to the university community (O' Shea et al., 2015). A critical factor for influencing student engagement is lifeload, which Kahu (2013, p.797) defines as "the sum of all the pressures a student has in their life, including university". Support from family and friends in order to gain time and space to study is crucial to online student success.

\section{Psychosocial}

Online student engagement is affected by a number of interrelated psychosocial influences such as teaching support, study skills and time management skills. Effective teaching support which encourages connection, presence and through synchronous and asynchronous approaches has a positive effect on online student engagement (Stone \& O'Shea, 2019). Study skills such as organisation, time management and digital skills play contribute to online student success (Farrell \& Brunton, 2020; Farrell \& Seery, 2019). Online students who create a structured study routine and a quiet study environment which is balanced with their other responsibilities are more likely to positively engage with their studies (Buck, 2016).

\section{Engagement vs. Disengagement}

The outcomes of online student engagement are a positive learning experience, course completion and a sense of satisfaction (Kahu, 2013; O' Shea et al., 2015). The outcomes of online student disengagement are non-completion, withdrawal, and unsatisfactory learning experience (Kahu, 2013; O' Shea et al., 2015). The majority of students who withdraw do not return to study, emphasising the importance of targeted student success and engagement supports early in the study lifecycle (Brunton et al., 2018) 


\section{Methodology}

The design of the study was a qualitative case study, and was framed by the following research question:

What themes are central to online student engagement experiences?

Data was collected via student eportfolio entries and via semi-structured interviews over the course of the academic year 2016-17. Twenty four students consented to take part in the study. Data was analysed following a data led thematic approach and involved iterative cycles of coding and analysis (Braun \& Clarke, 2006). Four themes were constructed through the analytic process and are discussed in the finding section below.

\section{Findings}

The five central themes that make up the study's findings highlight key issues of students' sense of community, their support networks, balancing study with life, confidence, and their learning approaches,

\section{Community}

The data revealed that community was perceived by participants to be an important source of support and contributed positively to their learning experience. Formal and informal communities developed in the course which included student generated WhatsApp groups, study groups and the formal course discussion forums.

I: Ok that's interesting. And then evidence 2 is your WhatsApp group.

P19: I need those women, that's my cohort. We are in contact most days supporting one another. Like when I was feeling down and I was thinking I do not want to do this course anymore it's too much, they were like you're great and you're smart. I read your post, your post is really insightful. If I don't understand a concept we can discuss it. If WhatsApp isn't sufficient we can ring each other.

I: So your study group is really important.

P19: It's not a study group. My sister when she did her they give you a cohort you do all your classes together. You do all your study groups together, projects together. There's something about that approach that makes you feel like you're part of a supportive group.

I: You're in something greater than yourself?

P19: Yeah (P19 Interview 1)

\section{Online Teacher Support}

The central role of the online teacher as a source of support was strongly articulated by participants in their narratives. The role of the online teacher as a source of social, academic and pastoral support was very significant to the learning experience of participants in terms of clarification of concepts and assignments, encouragement, guidance on reading and approaches to study.

"As I had been studying these subjects in the unit notes, it was very useful to have a structured discussion on them. When our tutor gives real life examples of the application of these, it makes everything easier to understand and remember" (P8, eportfolio entry 4) 


\section{Balance}

Balancing study with work and caring responsibilities was reported by participants to be the most challenging aspect of learning online. Walking the tightrope of finding time to study, complete assignments with work and family commitments caused a lot of pressure for this cohort of online students.

"For the first time since taking up third level education again, I found it very difficult to juggle my work demands, assignment demands and minor ill health." (P7, eportfolio entry 2)

Issues with time management were very prevalent in the data, and was a persistent challenged face by participants over the course of the academic year.

"It all comes down to time management, which I remember was an issue at this time last year. With all the extra pressures of Christmas from a work and family point of view the study can get squeezed. I may have to do less(no?) housework to facilitate my learning this month. This idea has not been negotiated with my partner and may have to be revised!" (P20, eportfolio entry 2)

\section{Learning approaches}

The data from the online student eportfolio entries reveals very personal and innovative approaches to learning and gives an insight into when, how and where online students study.

"I find if I cannot grasp a piece of information through one format, i.e. reading a text, sometimes watching a YouTube video regarding the topic can really help me comprehend the material better." (P2, eportfolio entry 3)

Participants included many visual examples of their notetaking approaches in the evidence part of their eportfolio entries, it is striking is how individual each note taking approach was, this is evident in figure 2 below.

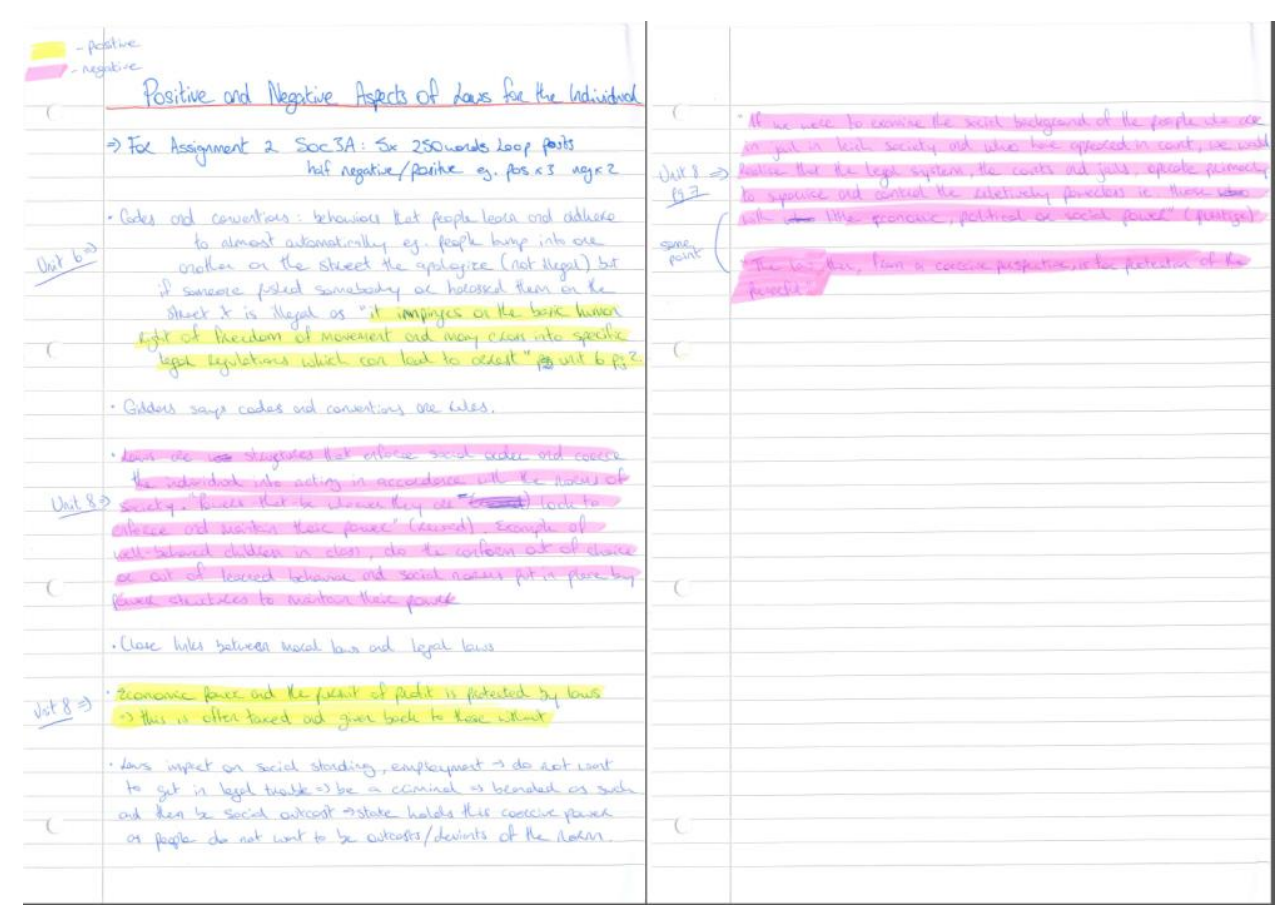

Figure 2. Notetaking example

In addition, participants reported studying in a wide range of places. They studied at home, in the library, on their phone while commuting to work, in cafes, in work, and sitting on the side of football pitch. In their eportfolio entries, many participants included images of their study spaces, for example figure 3 below. 


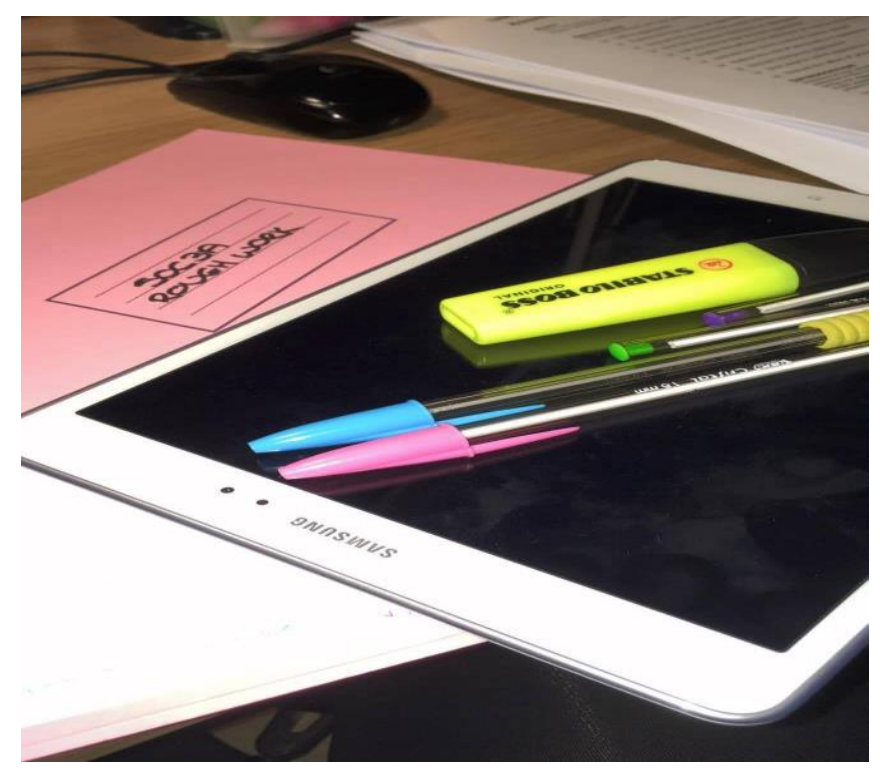

Figure 3. Participant study space

\section{Discussion}

The findings of this study indicate that successful online student engagement was influenced by structural factors such as lifeload and course design. This is consistent with the literature which found balancing multiple roles can cause online students to experience considerable stress (Brown et al., 2015). Further, online student engagement was influenced by psychosocial factors such as peer community, online teacher support and study skills and time management. These findings are consistent with previous research on peer interaction in online courses carried out by O'Shea, Stone, Delahunty (2015) and the value of informal student networks for online students has been evidenced by Zembylas et al. (2008).

\section{Concluding thoughts}

The purpose of this study was to explore online student engagement experiences in Irish higher education. The findings of this study indicate that being a successful online student was impacted by both structural factors such as lifeload and psychosocial factors like community. Although this study is a small in-depth qualitative study, its findings provide insights into how online degree programmes can support online students to achieve successful and fulfilling learning experiences.

\section{References}

Braun, V., \& Clarke, V. (2006). Using thematic analysis in psychology. Qualitative Research in Psychology, 3(2), 77-101. https://doi.org/10.1191/1478088706qp063oa.

Buck, S. (2016). In their own voices: Study habits of distance education students. Journal of Library \& Information Services in Distance Learning, 10(3-4), 137-173. doi:10.1080/1533290X.2016.1206781

Brown, M., Hughes, H., Keppell, M., Hard, N., \& Smith, L. (2015). Stories from Students in Their First Semester of Distance Learning. International Review of Research in Open and Distributed Learning, 16 (4), 1-17.

Brunton, J., Brown, M., Costello, E., \& Farrell, O. (2018). Head start online: flexibility, transitions and student success. Educational Media International, 55 (4), 347-360 doi: 10.1080/09523987.2018.1548783 
Delaney, L., \& Farren, M. (2016). No 'self' left behind? Part-time distance learning university graduates: Social class, graduate identity and employability. Open Learning: The Journal of Open, Distance and e-Learning, 31(3), 194-208. https://doi.org/10.1080/02680513.2016.1208553.

Farrell, O., \& Seery, A., (2019). "I am not simply learning and regurgitating information, I am also learning about myself": learning portfolio practice and online distance students. Distance Education, 40 (1). doi: 10.1080/01587919.2018.1553565

Farrell, O., Brunton, J. (2020). A balancing act: a window into online student engagement experiences. Int J Educ Technol High Educ 17, 25. https://doi.org/10.1186/s41239-020-00199-x

Kahu, E. R., Stephens, C., Zepke, N., \& Leach, L. (2014). Space and time to engage: Mature-aged distance students learn to fit study into their lives. International Journal of Lifelong Education, 33(4), 523-540. doi:10.1080/02601370.2014.884177

Kahu, E. R. (2013). Framing student engagement in higher education. Studies in Higher Education, 38(5), $758-$ 773. https://doi.org/10.1080/03075079.2011.598505.

O' Shea, S., Stone, C., \& Delahunty, J. (2015). "I 'feel' like I am at university even though I am online." exploring how students narrate their engagement with higher education institutions in an online learning environment. Distance Education, 36(1), 41. doi:10.1080/01587919.2015.1019970

Zembylas., M., Theodorou, M., Pavlakis, A. (2008). The Role of Emotions in the Experiences of Online Learning: Challenges and Opportunities. Educational Media International, 45 (2), 107-117. doi: 10.1080/09523980802107237 